\title{
Saberes experienciales para una nueva acción pedagógica: narrativas de una práctica docente mediada por las tecnologías
}

\author{
Fernando Roberto Amorim Souza \\ fernandoamorim.ifpr@gmail.com \\ http://orcid.org/0000-0003-2969-5371 \\ Universidade Tecnológica Federal do Paraná - UTFPR \\ Nuria Pons Vilardell Camas \\ nuriapons@gmail.com \\ https://orcid.org/0000-0003-3992-7914 \\ Universidade Federal do Paraná - UFPR \\ João Amadeus Pereira Alves \\ japalves@yahoo.com.br \\ https://orcid.org/0000-0002-1850-0260 \\ Universidade Tecnológica Federal do Paraná - UTFPR
}

Recibido: 29/marzo/2021 Aceptado: 24/agosto/2021

\begin{abstract}
Resumen
Este trabajo analiza el cambio de la práctica docente de un profesor de Geografía, escuela secundaria, en una escuela pública, motivado por el desánimo de los resultados de su propia labor pedagógica y la antipatía de los alumnos a las clases magistrales, ante una escuela que preserva el tradicionalismo, insiste en no formar al profesor y al alumno, acudiendo a la racionalidad técnica y disidente de un nuevo tiempo perfilado por la cultura digital y permeado por la presencia de las tecnologías. La investigación trata de responder, como pregunta principal, ¿cuál es la percepción de los alumnos en relación con su propio aprendizaje, utilizando recursos tecnológicos digitales en sustitución de las clases tradicionales y expositivas? Pretende comprender la percepción del alumno para el desarrollo de una nueva acción pedagógica, haciendo uso del concepto de Aprendizaje Colaborativo y de recursos como la Curaduría del Conocimiento y los Recursos Educativos Abiertos. Se trata de una investigación de enfoque cualitativo, de carácter empírico y que utiliza el método de las cartas narrativas. Al final se comprobó que una práctica docente innovadora favorece el aprendizaje a partir de la motivación de los alumnos y la satisfacción del profesor con el desempeño de su trabajo
\end{abstract}

Palabras clave: Saber del docente. REA. Curaduría. Aprendizaje colaborativo.

\section{Saberes experienciais para uma nova ação pedagógica: narrativas de uma prática docente mediada por tecnologias}

\begin{abstract}
Resumo
O presente trabalho analisa a mudança da prática docente de um professor de Geografia em uma escola pública de Ensino Médio, motivado pelo desânimo dos resultados do seu próprio fazer pedagógico e da antipatia dos estudantes às aulas expositivas, diante de uma escola que preserva o tradicionalismo, insiste em não formar o docente e discente, voltando-se à racionalidade técnica e dissidente de um novo tempo que é delineado pela cultura digital e permeado pela presença das tecnologias. Esta pesquisa tenta responder à questão: qual a percepção dos alunos em relação a sua própria aprendizagem, utilizando recursos da tecnologia digital em substituição das aulas tradicionais e expositivas? Tem como objetivo
\end{abstract}


compreender a percepção do aluno para o desenvolvimento de uma nova ação pedagógica, valendo-se da concepção da Aprendizagem Colaborativa e de recursos como a Curadoria do Conhecimento e Recursos Educacionais Abertos. Trata-se de uma pesquisa de abordagem qualitativa, de cunho empírico e utilizou-se do método de cartas narrativas. Constatou-se ao final que uma prática docente inovadora favorece a aprendizagem a partir da motivação dos alunos e da satisfação do professor com o desempenho do seu trabalho.

Palavras chave: Saber docente; REA; Curadoria; Aprendizagem colaborativa.

\title{
Experiential knowledge for a new pedagogical action: narratives of a teaching practice mediated by technologies
}

\begin{abstract}
This paper analyses a teaching practice change of a public high-school geography teacher, motivated by his discouragement with the results obtained from his own pedagogical practice and the student's dislike for expositive classes, before a school which preserves traditionalism, insists on not training teachers and students, focusing in a rationality that is technical and dissident to a new age outlined by digital culture and permeated by the presence of technology. This study attempts to aswer the following question: what is the students' perception related to their own learning about using digital technology resources as a replacement of traditional and expositive classes? It aims to understand the perception of students for the development of a new pedagogical practice, through Collaborative Learning and of resources such as Curatorship of Knowledge and Open Educational Resources. It is an empirical and qualitative research which uses the narrative cards method. It was found that a innovative teaching practice favors learning based on students' motivations and on teacher's satisfaction with work performance.
\end{abstract}

Keywords: Teaching knowledge; OER; Curatorship; Collaborative learning.

\section{Introdução}

A inovação da prática docente é uma tarefa complexa que requer concentração, esforço do professor e tempo de estudos teóricos para indicar um caminho na sua prática pedagógica. Tendo em vista a excessiva carga horária de grande parte dos professores, há, também, o acréscimo de outras atribuições burocráticas para justificar a própria atividade docente, muitas vezes deixando-os sem o tempo necessário para sua aprendizagem e possível evolução no campo de atuação profissional. Neste sentido, é deveras a afirmação feita por Beck (2017) ao apresentar sua pesquisa sobre o peso da intensificação do trabalho docente e constatar que as constantes pressões sobre o trabalho do professor acabam por rotinizar sua prática devido ao reduzido espaço que ele tem para exercer seu profissionalismo. Com efeito, o autor identifica o ensino como uma ocupação altamente estressante e de insatisfação por parte dos professores.

Dessa forma, a ousadia de inovar não é um mero desejo, mas, sobretudo pela falta de condições, é uma questão de cunho físico e até mesmo psicológico (Beck, 2017). Por sua vez, essa condição acomoda o professor e o resultado da sua prática acaba voltando-se quase 
exclusivamente ao conteudismo ${ }^{1}$. Não muito raro, dedica-se na sala de aula à reprodução de conteúdos, algo que Freire (1974) de forma análoga chamou de educação bancária, ou seja, estudantes passivamente ouvem, leem, copiam, reproduzem toda a orientação passada pelo professor.

Entretanto, vários professores têm se preocupado com essa situação do fracasso escolar, o que também lhes causa estresse. Segundo a pesquisa de Beck (2017), o sentimento desses profissionais é de não estar ensinando, isto é, de apenas passar o tempo. Outro problema que pode ser apontado é a busca de alternativas em receituários de aulas prontas, geralmente, em sites da internet, em revistas ou outros meios que se especializaram em vender a fórmula para o sucesso docente, reforçando a ilusória homogeneização da educação. Do mesmo modo, também não é rara a utilização dos planejamentos de ensino dos anos anteriores. Não há tempo para fazer novos planejamentos e, quando eles se fazem necessários, geralmente a ação do professor limita-se a remendos, acrescentando ou retirando algum tema do documento pedagógico.

As práticas e políticas educacionais em geral têm se balizado em dar resposta aos processos produtivos, reproduzindo e legitimando formas de dominação hegemônica, reduzindo a complexidade humana à mera concepção de produtividade (Santomé, 1998; Bourdieu, 1992). Porém, essa concepção tem criado constantes tensões na escola, onde se vive um paradigma entre continuar a atender as demandas do capital e da lógica cartesiana ou da pressão social decorrente da sua própria dinâmica. Alguns jovens estudantes têm demonstrado aversão aos princípios da racionalidade reducionista, um ensino voltado à racionalidade técnica (Schön, 2000; Tardif, 2002), cuja preocupação se limita à formação profissional rigorosa para dar respostas imediatas a problemas instrumentais.

Não obstante, os estudantes estão imersos em redes virtuais que os conectam a informações de forma bem peculiar para além da sala de aula. É essa nova sociedade que Camas et. al (2013) definem como a Era da Cultura Digital, destacando que a extensão digital do ser humano, interligado à internet, acaba por dimensionar novos cidadãos desta era. Duas observações importantes são trazidas pelas autoras: a cultura do digital promove a necessidade da criação de mais tecnologias digitais e a atual geração (chamada por elas de interativa) tem intimidade demasiada com as tecnologias digitais, transcendendo o espaço

\footnotetext{
${ }^{1} \mathrm{O}$ conteudismo é uma expressão que serve para demonstrar a hierarquização da relação aluno e professor, cabendo a este a transmissão do conhecimento para o aluno, cujo foco é o total e restrito cumprimento dos conteúdos descritos no currículo da disciplina, quase sempre descontextualizados da realidade do aluno e sem diálogo com outras disciplinas que compõem a grade curricular da escola. Mais recentemente, passou a ser chamada matriz curricular para mudar a concepção literal de uma gaiola curricular.
} 
geográfico, físico e até mesmo a própria economia. Diante disso, ainda existem aspectos negativos que devem ser observados, como o perigo da não neutralidade das tecnologias, que "urge a necessidade de se construir uma concepção de Educação" (Camas et al, 2013, p. 182), em se tratando das tecnologias, com intencionalidades pedagógicas.

A cibercultura ${ }^{2}$, cultura influenciada pelo ciberespaço, demonstra que os processos tradicionais de aprendizagem se tornam, de certa forma, obsoletos em função de uma série de fatores. Entre eles estão a necessidade de renovação dos saberes, a nova configuração do mundo do trabalho e o ciberespaço, que suporta tecnologias intelectuais que amplificam, exteriorizam e modificam numerosas funções cognitivas humanas.

A presente pesquisa foi desenvolvida a partir da experiência com tecnologias digitais em aulas de geografia do ensino médio, com o uso de uma plataforma de ensino e aprendizagem, Curadoria e Recursos Educacionais Abertos (REA), balizada pelo princípio da aprendizagem colaborativa. Vale destacar que a Curadoria de Conhecimento se torna uma importante estratégia para a atuação docente na Era da Cultura Digital (Camas et al. 2013) e consiste, a partir do ciberespaço, que o professor possa selecionar, caracterizar e compartilhar informações para, posteriormente, organizá-las e transformá-las em conhecimento acessível (Fofonca e Camas, 2019).

Assim, o cerne da investigação teve o propósito de descortinar algumas respostas a indagações relacionadas à autonomia do professor no seu fazer pedagógico e à construção de saberes que contribuam para uma formação que possibilite pensar e repensar a prática docente frente aos desafios diários da sala de aula, inclusive na dimensão cibercultural. A partir dessa experiência, busca-se dialogar com os resultados que ela promoveu, na construção significativa de saberes que influenciaram e influenciam a prática docente frente a uma crise do profissionalismo (Tardif, 2002) e outras crises profissionais multifacetadas (Moraes, 2015) presentes na educação.

A epistemologia da prática docente, enfoque teórico trazido por Tardif (2002), pode ser uma alternativa viável para superar a crise do profissionalismo atual e fortalecer a identidade e autonomia do professor. Os saberes experienciais, ou seja, a bagagem construída em coletivo com seus pares, seus alunos no seu dia a dia na escola e na sociedade, que o docente traz ao longo da sua trajetória profissional, elencam consigo elementos que favorecem o diálogo para construção de uma formação docente reflexiva. Isso conduz a uma

\footnotetext{
${ }^{2}$ Lévy (2009) define cibercultura como um conjunto de técnicas (materiais e intelectuais), de práticas, de atitudes, de modos de pensamento e de valores que se desenvolvem com o crescimento do ciberespaço. Este, por sua vez, é orientado pela interconexão, a criação de comunidades e a inteligência coletiva.
} 
prática alinhada com as exigências sociais e que pode responder ao que alunos esperam do professor. Busca-se demonstrar, apesar das dificuldades interpostas no trabalho docente, os seguintes aspectos: excesso de burocracia, vigilância sobre o cumprimento do horário, as amarras curriculares, as cobranças sociais pela hipotética doutrinação, bem como se há possibilidade de inovação pedagógica, considerando a experienciação do professor e a autoformação sobre educação e tecnologias. A reflexão da prática docente pode frutificar em ações didáticas e pedagógicas significativas para o aluno e para o professor.

\section{A estrutura da pesquisa}

A presente investigação se ampara na abordagem qualitativa e empírica (Creswell, 2010, 2014; Bardin, 2011). Fez-se o recorte a partir da inovação pedagógica na sala de aula, vivenciada por um dos autores deste trabalho, doravante denominado de professorpesquisador, na disciplina de Geografia no Ensino Médio, em uma instituição de ensino público federal. A pesquisa foi orientada de forma a compreender a seguinte questão: qual a percepção dos alunos em relação a sua própria aprendizagem, utilizando recursos da tecnologia digital como substituição das aulas tradicionais e expositivas?

O instrumento para coleta dos dados se deu por meio de cartas narrativas desenvolvidas pelos alunos, nas quais discorreram a respeito das suas experiências com a adoção da ação pedagógica proposta pelo professor-pesquisador. As cartas narrativas, para Souza e Cabral (2015), são adotadas enquanto recurso para reconstituir a memória pedagógica e das práticas educativas adotadas. Para Camas et. al (2020), a adoção de tais cartas se justifica pela troca de experiências vivenciadas por um ou mais sujeitos em determinado tempo e espaço, tendo a possibilidade de construir e reconstruir significados, constituindo-se como importante instrumento para análise da situação experimentada. A carta narrativa, denominada pedagógica por Lima (2006), cria “[...] um clima de confidência e intimidade, que os preservaria de julgamento" (idem, p. 139). Para o mesmo autor (p. 140), a narrativa pode representar a "voz à maioria dos docentes, possibilitando [...] maior contato com as ideias do professor em formação e de sua relação com o conhecimento e com a leitura que faz da vida e do mundo em que vive". Portanto, entender os significados experienciais do sujeito é fundamental para situar a ação do docente e do discente e o impacto relacionado à sua capacidade cognitiva.

A narrativa é um dos meios pelo qual a linguagem é expressa, por esta razão Clandini e Connelly (1996) concebem a narrativa como uma perspectiva de método por possibilitar 
reflexões e deliberações, dentre outros elementos. Para Camas et. al (2020), a narrativa, como expressão da subjetividade, permite ao sujeito compartilhar suas histórias de vida e traz ao pesquisador reflexões e indicativos de deliberações a partir da sua análise.

A análise dos dados se deu na perspectiva bardaniana da análise de conteúdo. Para Bardin (2011) o objetivo deste método é desvendar de maneira crítica diferentes fontes de dados a partir de um conjunto de técnicas e organizá-las sistematicamente para se proceder a análise das comunicações.

\section{A sala de aula como fonte dos saberes experienciais e o contexto da pesquisa}

Inicialmente, consideramos importante trazer as concepções de Tardif (2002), pois apresenta a necessidade de consciência a respeito do movimento de profissionalização do ensino em toda a problemática da formação de professores. Trata da crise do conhecimento, crise das técnicas e crise de estratégias (Tardif, 2002). Segundo o autor, uma das causas dessa crise está relacionada à perícia profissional, a formação fragmentada em disciplinas que não se mostra capaz de promover uma formação voltada à realidade profissional, e à conflitante desconfiança do público nas profissões e nos profissionais. Diante desse contexto, na epistemologia da prática, o autor denomina como o "estudo do conjunto dos saberes utilizados realmente pelos profissionais em seu espaço de trabalho cotidiano para desempenhar todas as suas tarefas" (Tardif, 2000, p. 10). Logo, os saberes constituem tudo que possa aglutinar conhecimentos, atitudes, competências, habilidades, ou seja, o saber, o saber-ser e o saber-fazer.

De acordo com os saberes classificados e definidos por Tardif (2002), selecionamos para este estudo os saberes experienciais. Ao contrário dos demais saberes, que são externos e o professor não tem controle sobre sua produção e circulação. A construção dos saberes experenciais é feita através da própria prática no cotidiano do professor, capacitando-o para suas decisões diárias, a partir da interpretação das diferentes situações que ocorrem na sala de aula, permitindo-lhe criar estratégias e alternativas de sucesso. Para Gauthier et. al (2013, p. 28) "é muito mais pertinente conceber o ensino como a mobilização de vários saberes que formam uma espécie de reservatório no qual o professor se abastece para responder a exigências específicas de sua situação concreta de ensino".

Mesmo cultivando esses saberes, principalmente os saberes experienciais que vão sendo produzidos ao longo dos anos letivos, sobretudo, é necessário fazer, na sala de aula, um exercício de reflexão para uma possível tomada de decisão futura. Foi o que aconteceu 
com o professor desta pesquisa, doravante denominado professor-pesquisador. Nas reflexões acerca do seu próprio trabalho docente e frente à falta de motivação dos alunos, deparou-se com a necessidade da adoção de outros procedimentos pedagógicos. Valendo-se do conjunto de saberes, buscou amparo teórico e desenvolveu uma nova ação pedagógica a partir do ensino colaborativo, da curadoria da aprendizagem, de recursos da tecnologia digital, bem como dos REA, com o principal intuito de conectar os alunos às novas tendências educacionais, dado o advento da internet e das tecnologias digitais.

Buscou-se, também, sair do conteudismo escolar, valorizar as experiências de cada um dos alunos vivenciadas nos seus contextos sociais e explorar os recursos pedagógicos de forma híbrida, para uma maior motivação e melhoria da aprendizagem. No caso, extrapolouse tempo e espaço, demonstrando que a aprendizagem não se limita à sala de aula. Para a juventude contemporânea, o presencial e o virtual muitas vezes se confundem. A tradição conservadora da escola, apoiada no ensino de disciplinas desconectadas entre si e do mundo, (Santomé, 1998) foi um dos elementos observados pelo professor-pesquisador como desmotivador tanto para o aluno quanto para si, ao deparar-se com a sensação de inutilidade do seu trabalho.

O professor-pesquisador procurou desenvolver um processo de ensino e aprendizagem balizado pelo princípio colaborativo, partindo do pressuposto que a força motriz do atual neoliberalismo é desencadear a individualidade e concorrência mútua (Van Der Linden et. al, 2000), aprender não apenas a geografia, mas também exercitar e valorizar a cultura da colaboração nesse complexo cenário esfacelador. Tal cenário, propositalmente estimulado pelo capitalismo, reduz os sujeitos a meros seres pragmáticos desprovidos de senso crítico, guiando pela reafirmação de valores conservadores, buscando a eficácia, a crença no funcionamento do mercado e a individualização (Van Der Linden et. al, 2000).

Partindo do conceito de Maturana e Varela (2002) e Fiorentini (2004), a aprendizagem cooperativa é aqui entendida como a divisão de trabalho individual de cada membro de um grupo e, ao cabo de um dado projeto, unem-se as partes de modo a concluirse a atividade proposta. Já a colaboração, vai além de um simples trabalho em grupo, com divisão de trabalhos individuais. A colaboração não é compreendida como uma relação hierárquica ${ }^{3}$, na qual se impõem tarefas; "mas uma relação entre pessoas que saibam ouvir,

\footnotetext{
${ }^{3}$ É importante ressaltar que o estudo foi realizado com 40 alunos em cada sala de aula, tempo hora-aula determinado, o que levou o professor-pesquisador a desenvolver a estratégia de rotação por estação na formação dos grupos. Mesmo que o professor tenha indicado, inicialmente, a escolha dos grupos de alunos, todos os alunos puderam passar por todos os grupos criados pela própria estratégia adotada. Deste modo acredita-se que não se impôs um grupo único aos alunos e todos tiveram a oportunidade de poder participar da
} 
compartilhar ideias e trabalhar unanimemente, permitindo que haja uma constante interação entre os membros do grupo" (Kemczinski et al., 2007, p. 4). Portanto, a aprendizagem colaborativa, nesta perspectiva, pode estimular a dialogicidade a partir da interação recíproca, da troca de experiências e compartilhamento de saberes. Para Panitz (1996), não se trata de uma técnica, mas de uma filosofia de interação e estilo de vida.

Assim sendo, o professor dividiu a turma em dez grupos. Toda temática a ser trabalhada no ano, conforme a ementa curricular, também foi dividida em dez momentos, denominados por ele de ciclos. Considerando os duzentos dias letivos, cada ciclo teve duração de vinte dias letivos. No início do ano letivo, todos os alunos já ficaram sabendo da sua disposição nos grupos, a e consta na figura 1.

Figura 1 - Distribuição dos alunos nos grupos

\begin{tabular}{|c|c|c|c|c|}
\hline \multicolumn{5}{|c|}{ CICLO 1} \\
\hline TEMA & \multicolumn{4}{|c|}{ ALUNOS } \\
\hline 1 & A1 & A11 & A21 & A31 \\
\hline 2 & $A 2$ & A12 & A22 & A32 \\
\hline 3 & $A 3$ & A13 & A23 & $A 33$ \\
\hline 4 & A4 & A14 & A24 & A34 \\
\hline 5 & A5 & A15 & A2S & A3S \\
\hline 6 & AG & A16 & A2E & A36 \\
\hline 7 & A7 & A.17 & A27 & $A 37$ \\
\hline 8 & $A 8$ & A18 & A28 & $A 38$ \\
\hline 9 & A9 & A19 & A29 & A39 \\
\hline 10 & A10 & A20 & A30 & A40 \\
\hline \multicolumn{5}{|c|}{ CiCLOO 6} \\
\hline TEMA & \multicolumn{4}{|c|}{ ALUNOS } \\
\hline 1 & $A G$ & A16 & A30 & A36 \\
\hline 2 & A7 & A17 & A21 & A37 \\
\hline 3 & $A 8$ & A18 & A22 & A38 \\
\hline 4 & A9 & A19 & A23 & A39 \\
\hline 5 & A10 & A20 & $A 24$ & A40 \\
\hline 6 & A1 & A11 & $A 25$ & A31 \\
\hline 7 & $A 2$ & A12 & A26 & A32 \\
\hline 8 & $\mathrm{~A} 3$ & A13 & $A 27$ & A33 \\
\hline 9 & A4 & A14 & A28 & A34 \\
\hline 10 & A5 & A15 & A29 & A35 \\
\hline
\end{tabular}

\begin{tabular}{|c|c|c|c|c|}
\hline \multicolumn{5}{|c|}{ CICLO 2 } \\
\hline TEMA & \multicolumn{5}{|c|}{$A L U$ NOS } \\
\hline 1 & $A 10$ & $A 12$ & $A 29$ & $A 38$ \\
\hline 2 & $A 1$ & $A 13$ & $A 30$ & $A 39$ \\
\hline 3 & $A 2$ & $A 14$ & $A 21$ & $A 40$ \\
\hline 4 & $A 3$ & $A 15$ & $A 22$ & $A 31$ \\
\hline 5 & $A 4$ & $A 16$ & $A 23$ & $A 32$ \\
\hline 6 & $A 5$ & $A 17$ & $A 24$ & $A 33$ \\
\hline 7 & $A 6$ & $A 18$ & $A 25$ & $A 34$ \\
\hline 8 & $A 7$ & $A 19$ & $A 26$ & $A 35$ \\
\hline 9 & $A 8$ & $A 20$ & $A 27$ & $A 36$ \\
\hline 10 & $A 9$ & $A 11$ & $A 28$ & $A 37$ \\
\hline \multicolumn{5}{|c|}{ CICLO 7 } \\
\hline TEMA & \multicolumn{3}{|c|}{$A L U N O 5$} \\
\hline 1 & $A 5$ & $A 17$ & $A 28$ & $A 33$ \\
\hline 2 & $A 6$ & $A 18$ & $A 29$ & $A 34$ \\
\hline 3 & $A 7$ & $A 19$ & $A 30$ & $A 35$ \\
\hline 4 & $A 8$ & $A 20$ & $A 21$ & $A 36$ \\
\hline 5 & $A 9$ & $A 11$ & $A 22$ & $A 37$ \\
\hline 6 & $A 10$ & $A 12$ & $A 23$ & $A 38$ \\
\hline 7 & $A 1$ & $A 13$ & $A 24$ & $A 39$ \\
\hline 8 & $A 2$ & $A 14$ & $A 25$ & $A 40$ \\
\hline 9 & $A 3$ & $A 15$ & $A 26$ & $A 31$ \\
\hline 10 & $A 4$ & $A 16$ & $A 27$ & $A 32$ \\
\hline
\end{tabular}

\begin{tabular}{|c|c|c|c|c|}
\hline \multicolumn{5}{|c|}{ CICLO 3 } \\
\hline TEMA & \multicolumn{3}{|c|}{$A L U N O 5$} \\
\hline 1 & $A 9$ & $A 13$ & $A 27$ & $A 35$ \\
\hline 2 & $A 10$ & $A 14$ & $A 28$ & $A 36$ \\
\hline 3 & $A 1$ & $A 15$ & $A 29$ & $A 37$ \\
\hline 4 & $A 2$ & $A 16$ & $A 30$ & $A 38$ \\
\hline 5 & $A 3$ & $A 17$ & $A 21$ & $A 39$ \\
\hline 6 & $A 4$ & $A 18$ & $A 22$ & $A 40$ \\
\hline 7 & $A 5$ & $A 19$ & $A 23$ & $A 31$ \\
\hline 8 & $A 6$ & $A 20$ & $A 24$ & $A 32$ \\
\hline 9 & $A 7$ & $A 11$ & $A 25$ & $A 33$ \\
\hline 10 & $A 8$ & $A 12$ & $A 26$ & $A 34$ \\
\hline \multicolumn{5}{|c|}{ CICLO 8} \\
\hline TEMA & \multicolumn{3}{|c|}{$A L U N O 5$} \\
\hline 1 & A4 & $A 18$ & $A 26$ & $A 40$ \\
\hline 2 & $A 5$ & $A 19$ & $A 27$ & $A 31$ \\
\hline 3 & $A 6$ & $A 20$ & $A 28$ & $A 32$ \\
\hline 4 & $A 7$ & $A 11$ & $A 29$ & $A 33$ \\
\hline 5 & $A 8$ & $A 12$ & $A 30$ & $A 34$ \\
\hline 6 & $A 9$ & $A 13$ & $A 21$ & $A 35$ \\
\hline 7 & $A 10$ & $A 14$ & $A 22$ & $A 36$ \\
\hline 8 & $A 1$ & $A 15$ & $A 23$ & $A 37$ \\
\hline 9 & $A 2$ & $A 16$ & $A 24$ & $A 38$ \\
\hline 10 & $A 3$ & $A 17$ & $A 25$ & $A 39$ \\
\hline
\end{tabular}
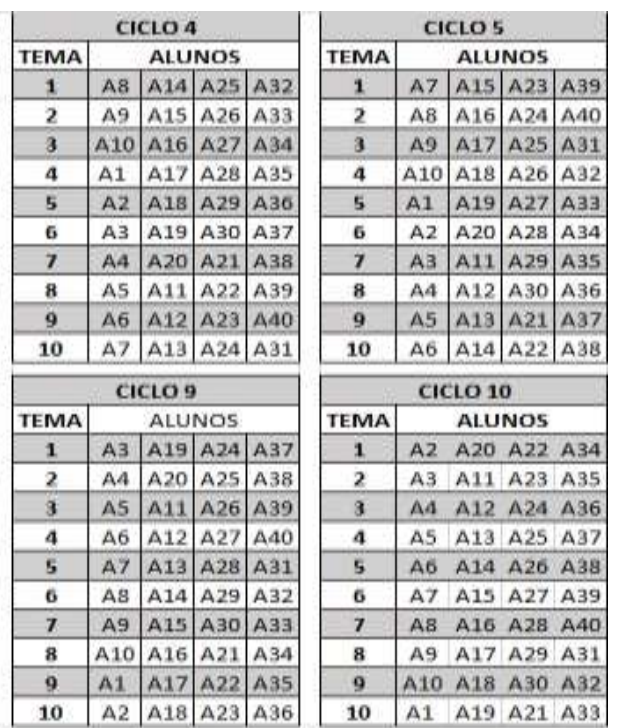

Legenda:

- Cada quadro da figura corresponde a um Ciclo, período de 20 dias letivos.

- A primeira coluna são os temas, ou seja, a ementa do curso foi dividida em dez temas a serem abordados ao longo de todo o ano letivo.

- As demais colunas representadas pela letra "A", são o aluno, o exemplo se refere a uma turma de 40 alunos.

Fonte: Elaborado pelos autores

Para deixar mais clara a distribuição dos alunos, conforme a figura 1, chamamos a atenção a disposição do aluno A1. Este aluno começa o primeiro ciclo com o tema 1 e nos

aprendizagem dos colegas de sala de aula. Portanto, ao se explicar as ações que se realizariam com os alunos, possibilitou-se não se impor a hierarquia que seria contrária à colaboração, experimentou-se uma estratégia de ação pedagógica que não teria como intenção privar a consciência, mas permitir a vivência cidadã na troca de todos com todos. 
ciclos seguintes alterna os temas e passa a fazer parte de grupos com colegas diferentes. Isso significa que tanto o aluno A1 quanto os demais estudantes passarão por todos os ciclos e todos os temas e todos os grupos. Esse revezamento não apenas ajuda na integração social da turma, como também evita vícios dos grupos fixos. Sobretudo, essa dinâmica de trocas de temas e grupos amplia a diversidade de ideias, ou seja, o que um estudante aprendeu no grupo anterior vai ajudar o grupo seguinte e, nisso, se converge uma diversidade de saberes e experiências adquiridas pelos alunos nos grupos anteriores. Aprendem não apenas o tema, mas os princípios da colaboração e de partilhar com todos de uma mesma sala, saber conviver.

O conteúdo deixa de ser algo rígido, engessado e entendido como um currículo que é caminho de aprendizagens (GOODSON, 2007). Em cada ciclo é realizado um momento de dialogicidade em torno do tema central, favorecido por uma educação digital em que as tecnologias têm muito a oferecer, inclusive para vencer as concepções cartesianas tão arraigadas na cultura escolar de reprodução mecânica e estratégias lineares e conteúdopadrão (Pérez Gómez, 2015). Por exemplo, o celular conectado à internet ${ }^{4}$ passa a ser instrumento indispensável na sala de aula. A esse respeito, cabe destacar que na nova era da informação (Castells, 2009; Cortella \& Dimenstein, 2015) as informações fluem veloz e infinitamente pelo ciberespaço.

Por essa razão, o professor-pesquisador definiu como estratégia a curadoria do conhecimento (ou da aprendizagem), não apenas na construção dos saberes escolares, mas na intenção de qualificar os alunos a fazerem escolhas responsáveis em meio a tantas informações, vinculadas aos saberes construídos e à prática docente. O que importa é saber o que importa (Cortella \& Dimenstein, 2015), isto é, para os autores não é função da escola levar os alunos a decorarem informações e sim desenvolver habilidades e capacitá-los ao senso crítico para fazer escolhas conscientes nessa cultura permeada pela comunicação e informação cada vez mais veloz, volumosa que circulam levando verdades e fake news.

A curadoria, de origem na museologia, avança para a educação sem perder o sentido pedagógico de mediar o sujeito ao objetivo a ser aprendido, desprezando os excessos. Como afirmam Fofonca e Camas (2019, p. 12) a curadoria do conhecimento está em "encontrar, agrupar, organizar e compartilhar o que há de melhor e mais relevante sobre um assunto, conhecimento ou uma abordagem". No entanto, na educação, em especial com advento das tecnologias digitais, a curadoria faz aportes de outros recursos muito presentes na

\footnotetext{
${ }^{4}$ Quanto ao acesso à internet, o professor adquiriu um roteador wifi para o uso dos alunos, que era ligado ao chegar na sala de aula.
} 
cibercultura e o apelo à educação aberta, a partir de ações e práticas que são modificadas pela exposição e uso de aparatos tecnológicos que intermediam o acesso ao ciberespaço, ou seja, ao lugar onde todas as informações e dados existem e para onde convergem e se materializam quando são acessadas, criam comunidades. É um ato de transformação desses dados em figuras, textos, sons (Martino, 2014). Assim, para o autor esse ato constitui uma troca de conhecimentos "que circulam, são modificados, reconstruídos, aumentados e editados de acordo com as demandas específicas de uma determinada situação" (p. 31) e conveniência também. Nessa perspectiva, os REA ganham notoriedade por serem "materiais de ensino, aprendizado e pesquisa, fixados em qualquer suporte ou mídia, que estejam sob domínio público e licenciados de maneira aberta, permitindo que sejam utilizados ou adaptados por terceiros" (UNESCO 5 , 2015, p.v.). Como se pode observar, a ação pedagógica do professor está amparada no seguinte tripé: aprendizagem colaborativa, curadoria da aprendizagem e REA, com suporte de tecnologias digitais.

Há quem diga: e se não cumprir o currículo? A Base Nacional Comum Curricular, enquanto uma diretriz de política pública, deve considerar de quais capacidades, competências e até mesmo habilidades os estudantes necessitam (Pérez Gómez, 2015). Contudo, não pode dizer como os professores devem colocar em prática esses aspectos, pois “esta é uma competência profissional deles: a capacidade de provocar o desenvolvimento das potencialidades únicas e diversificadas de cada aluno, amar a singularidade e adaptar o currículo às necessidades de cada aluno" (Pérez Gómez, 2015, p. 143). O autor traz, ainda, importante contribuição ao afirmar que a educação contemporânea deve focar na inovação, resolução de problemas, experimentação, criatividade, autoexpressão e trabalho em equipe.

Segundo essa diretriz, o papel do professor-pesquisador, neste processo, foi o de expor o aluno a situações de aprendizagem para buscar construir os saberes escolares. Para tanto, a ação pedagógica não se limitou a estudos na sala de aula, mas foram utilizados como recursos para interação o Google Sala de Aula ${ }^{6}$, Whats App e e-mail. No caso do Google Sala de Aula, também como repositório dos objetos curados ou produzidos, ou reutilizados ou remixados, bem como hiperlinks e videoaulas. Com isso, foram disponibilizados recursos para ajudar a aprendizagem, mas os alunos tiveram a liberdade da pesquisa.

\footnotetext{
${ }^{5}$ United Nations Educational, Scientific and Cultural Organization, traduzida oficialmente para a Língua Portuguesa como Organização das Nações Unidas para a Educação, a Ciência e a Cultura, em que é mantida a mesma sigla do idioma original.

${ }^{6}$ A opção por esta plataforma se deu em virtude da disponibilidade da instituição, mas em outros anos letivos foram usados outros recursos, como o Edmodo, por exemplo.
} 
A avaliação fugiu de tentativas características dos exames tradicionais, sendo uma autoavaliação do próprio aluno e da ajuda dos outros colegas. Esses momentos aconteceram sempre ao final de cada ciclo, em que cada grupo apresentou para os demais colegas o resultado das suas pesquisas e aprendizados.

A integração, isto é, a interdisciplinaridade com outras áreas do conhecimento (outras disciplinas escolares) foi algo importante. Como a gestão da aprendizagem passou a ser do próprio grupo, eles mesmos buscavam compreender determinado tema a partir de outras aulas, por exemplo ao estudar rochas e minerais, na Química; pressão atmosférica, na Física; cartografia, na Matemática; meio ambiente, na Biologia etc. Os próprios alunos buscavam explicações com os professores de outras disciplinas sobre o tema que eles estavam estudando. O desafio era poderem apresentar, no final do ciclo, o tema de maneira descomplicada para os demais colegas, na linguagem e compreensão deles.

\section{Análise e discussão das narrativas}

Vale aqui salientar que foi solicitado que os alunos narrassem de forma escrita ao professor as experiências relacionadas às atividades desenvolvidas, na sala de aula no decorrer de todo o ano letivo. De aproximadamente 90 alunos, 49 entregaram voluntariamente suas narrativas. Para além disso, cinco alunos procuram o professor para narrar suas impressões oralmente, sob o pretexto de não gostar de escrever.

$\mathrm{Na}$ análise, foram categorizadas as expressões: aula tradicional, criatividade, ludicidade, liberdade de aprender, trabalho em grupo e conteúdo. As categorias foram definidas considerando sua frequência nos textos, levando em consideração também as diferentes formas semânticas, foram analisadas a partir do sentido da expressão dentro da unidade de contexto, em suma, o que o sujeito quis dizer.

Liberdade de aprender, à primeira vista, se opõe à docência tradicional bancária e é confirmada pelos alunos sob análise. Para eles, ter a liberdade de aprender é buscar a aprendizagem a partir das curiosidades sobre si e sobre o mundo, em oposição a um ensino em que o professor transmite o conteúdo escolar de acordo com o que considera relevante, quase sempre sem conseguir conectar este com contextos socioculturais dos alunos, levandoos a meros processos mnemônicos. Um dos alunos narra que nunca havia entendido a razão para estudar relevo e qual a necessidade prática deste conteúdo além das perguntas das provas e exames de aprendizagem. No entanto, foi a partir da curiosidade de um fenômeno recorrente na sua comunidade (enchentes) que conseguiu relacionar com o tema relevo. Em 
suas palavras: "eu fiquei curioso e fui pesquisar mais a fundo o tema" $(\mathrm{C} 27)^{7}$. Destarte, Ausubel et. al (1983) ao explicar sobre a aprendizagem significativa, afirma que um novo assunto só terá sentido para um aluno quando ele consegue fazer interação com outros conceitos já existentes na sua cognição. Ou seja, o ensino deve partir do que o estudante já sabe e a liberdade de aprender constitui-se como um importante preceito para que ele saia do processo mecânico de memorização. Caberá ao professor influenciar a aprendizagem a partir do que o aprendiz já sabe (Ausubel et. al, 1983).

A ludicidade também é associada a termos como aprender com diversão, descontração e maior interação com o assunto. Esse é um ponto que está relacionado à criatividade e à motivação. A grande maioria dos alunos mostraram contentamento ao serem desafiados a construir criativamente objetos de aprendizagem, fazendo a aprendizagem ser maior. Dentre a ação pedagógica lúdica, incluíram-se atividades como jogos (não apenas o ato de jogar, mas a construção dos jogos pelos alunos), a produção de vídeos educativos, sempre com foco na interação com o outro. Santaella (2012), ao se referir ao comportamento lúdico, esclarece que a ludicidade é um importante componente na ligação dos processos cognitivos advindos da interação social do sujeito, como os rituais, a dança, o canto, o riso, estimulando emoções positivas, produzindo neurotransmissores responsáveis pelo bem-estar e alegria, envolvido na cooperação e competência social.

Nas palavras de alguns alunos: “o desenvolvimento de atividades lúdicas contribuiu para a formação do conhecimento" (I3); “...foi uma experiência interessante, porque mostrou que podemos aprender de forma descontraída e divertida" (C21); "a liberdade que você me deu foi essencial ao meu ano... a liberdade que você dá para que a nossa criatividade e poder de reflexão são muito importantes” (A1). Essa questão também está ligada a outra categoria analisada nas cartas narrativas: o trabalho em equipe.

$\mathrm{O}$ trabalho em equipe, aderente à proposta da aprendizagem colaborativa, à primeira vista revelou que o estudo está associado para os alunos a um ato solitário e individual. A demonstração vem em afirmações de alunos que relatam, inicialmente, não ter gostado da possibilidade de estudar em grupo, pois já estavam acostumados a estudar sozinhos. Este é um aspecto preocupante, do ponto de vista dos autores deste estudo, pois carece de estudo aprofundado, de modo a poder elucidar os impactos no processo de ensino e de aprendizagem, bem como social e psíquico dos alunos. Contudo, trabalhar em equipe é demonstrado como um ato de aprender a socializar-se, como expressa um deles: “...além de

\footnotetext{
7 Para as análises, os alunos foram indicados pela inicial da turma e número aleatório, evitando sua identificação.
} 
aprendermos, nos socializamos e aprendemos a trabalhar em equipe" (C20) e "Talvez seja necessário um maior estudo em relação a como fazer com que os adolescentes cooperem e aprendam a trabalhar em grupo" (A1).

Para além destas observações, a manifestação de contentamento é expressada pelos alunos à medida que se familiarizavam com o método, “...ao longo do ano percebi que aprendemos muito mais..." (C27); "todos os integrantes contribuíram para a elaboração de jogos e da pesquisa, tornando mais fácil o trabalho em grupo e facilitando o entendimento sobre o tema" (C11), ou seja, é preciso estimular e insistir no trabalho em grupo para que eles mesmos percebam os benefícios da produção com o outro e para o outro, como bem esclarece Vygotsky (1991, p. 99) "a aprendizagem humana pressupõe uma natureza social específica e um processo por meio do qual as crianças penetram na vida intelectual daqueles que as cercam". Vale registar relatos de contentamento expressados por alguns alunos em poder compartilhar com seus pares aquilo que aprenderam, como diz o aluno A12: "...estávamos responsáveis por 'ensinar' outras pessoas apenas com um jogo, o que não é uma tarefa simples. O resultado foi muito gratificante".

O rompimento com aulas expositivas foi um ponto destacado por quase todos os alunos e foi relacionado à forma de interação com o conteúdo da disciplina escolar. Para eles, aprender fazendo, ludicidade, estímulo à criatividade, liberdade para aprender e a socialização intensiva com os colegas são elementos que vão além da teoria e que prezam pelo que o aluno já sabe, possibilitando que houvesse a construção do saber escolar. Fugir das aulas expositivas para os alunos é: "Essas interações com os alunos fazem com que as aulas não sejam monótonas e muito teóricas. Aprender de modo prático e divertido faz com que o estudante goste de estudar, buscando cada vez mais o conhecimento" (A17); “...essas formas dinâmicas deixaram os alunos mais envolvidos e emprenhados...”.

Como dito anteriormente, aulas tradicionais e conteúdos estão correlacionados, pois as aulas expositivas seguem um rol de temáticas a serem seguidas e estabelecidas pelo currículo. Fugir desta possibilidade não significa um descompromisso com o currículo, muito pelo contrário, cria oportunidades para que os alunos relacionem temas e questões ao seu cotidiano, dando mais sentido a aprendizagem escolar. Como exemplo, o relato do aluno A30: "gosto muito da forma diferenciada que o senhor tenta nos transmitir esses vários conhecimentos sobre geografia, é uma forma peculiar, mas que faz com que o conteúdo se torne útil para os alunos e não apenas uma 'decoreba' de conceitos para obter nota na prova”.

A partir da análise das narrativas dos alunos, pode-se entender que novas metodologias de ensino exigem um profissional reflexivo que entenda a profissão docente 
como uma evolução contínua, conforme apontado por Tardif(2002). Demanda, também, um novo olhar ao momento e tempo que se vive para se aprofundar no processo de ensino e de aprendizagem, comprovando Camas e Brito (2017).

Conforme Moraes (2015), há uma patologia da escola que desconsidera os sujeitos em detrimento da supervalorização dos conteúdos, "apoiando o ato didático apenas em uma única visão ou dimensão da realidade falsamente objetiva e independente do ser, do viver/convier nos espaços educacionais" (Moraes, 2015, p. 17-18). De acordo com Sacristán e Gómez (2000, p. 68) "a exigência escolar de aprendizagem dos conteúdos disciplinares, não pode senão incorporá-los de maneira arbitrária, memorialística, superficial ou fragmentaria". A experiência do professor ao longo da sua carreira, o saber experiencial (Tardif, 2002), lhe propicia reflexões sobre seu próprio papel docente e auxilia na tomada de novas direções com objetivo de motivar a si e os seus alunos.

\section{Reflexões finais}

A postura reflexiva de um professor o faz pensar sobre sua própria prática em direção a ações que pudessem contribuir ainda mais na aprendizagem dos seus alunos. Foi nesta direção que este estudo apresentou o trabalho desenvolvido por um dos seus autores. Tal trabalho, foi feito a partir das suas experiências docentes que vão compondo um acervo dos saberes experienciais capazes de estimular reflexões sobre a sua prática e conceber o ensino como uma mobilização de vários saberes "que formam uma espécie de reservatório no qual o professor se abastece para responder a exigências específicas de sua situação concreta de ensino (Gauthier et al., 2013, p. 28), confirmando as afirmações de Tardif (2002). Qualquer ser humano pensa antes, durante e depois da sua prática, então a questão é se esse fato o faz um profissional reflexivo (Perrenoud, 2002). Ao serem considerados aspectos como o pouco tempo disposto para meditação docente, o calor da ação pedagógica e a pressão diária da sala de aula, a automatização torna-se quase inevitável.

A ideia de uma ação pedagógica inovadora emergiu a partir da percepção de certa apatia dos estudantes nas aulas de Geografia. Sensível a essa situação, o professorpesquisador passou a refletir sobre seu próprio papel e a função social da escola numa perspectiva transformadora e emancipatória. Nas palavras de Perronoud (2002), foi uma tomada de consciência, ou seja, o ato de refletir sobre a ação e ser capaz de ousar, mudar e romper com o senso comum ao inovar e transformar a própria prática. Esse é o ato de romper com o comodismo e conformismo, pois estes não pactuam com a chamada autonomia do 
professor. Concorda-se com Contreras (2012), a autonomia do professor começa na superação do fazer instrumental, ou seja, transpor o domínio da técnica e habilidades e, até mesmo, o repertório dos saberes teóricos para a compreensão que o fazer docente é um compromisso social e carrega no seu bojo relações sociais, afetivas e culturais.

A pesquisa também apontou outros elementos importantíssimos na educação atual: a cultura digital e as tecnologias digitais. Majoritariamente, os estudantes não se desligam dos seus celulares, tendo acesso rápido às informações e à interação social. Sendo esse um elemento presente em suas vidas, como observado, faz-se importante que o professor mobilize saberes docentes e aproveite essa situação em favor da aprendizagem escolar.

Diante dessa situação, a ação pedagógica desenhada pelo professor-pesquisador buscou dar conta, mesmo que minimamente, do desestímulo dos estudantes quanto ao ensino tradicional. Além disso, procurou formas para romper com as fragmentações do conhecimento e da racionalidade técnica, de modo a possibilitar aos estudantes a construção da aprendizagem a partir dos vários saberes, sem a supervalorização da memorização dos conteúdos disciplinares, mas que cumprisse o que é determinando pelo currículo da escola, sobretudo, caracterizando um estudo a partir da própria realidade.

O resultado dessa inovação pode ser visto no engajamento dos estudantes e na satisfação deles, que se traduz em estímulo para o professor, na necessidade de continuar refletindo sobre a própria prática, essencialmente, a partir dos saberes experienciais que apontam para uma condição reflexiva. Constituindo, com isso, profissionais capazes de superar a hegemonia imperativa na prática docente.

Pela pesquisa apresentada, é importante pensar a prática docente: a) pelo rompimento da hierarquia disciplinar do currículo fortemente estimulado pelo sistema educacional conservador que valoriza métodos preexistentes, sob o perigo de um ensino descontextualizado sem ligações e interações (Moraes, 2015); b) pela valorização da criatividade em detrimento do conteudismo, dando liberdade ao aluno ir ao encontro das suas próprias emoções, desejos e motivações para construir a aprendizagem a partir da sua própria bagagem cognitiva; c) pelo uso de tecnologias na prática educativa, o que estimula e mobiliza os alunos, como citado pelas narrativas dos mesmos, com atenção ao impacto do contexto mediado e midiatizado pelas tecnologias no processo de ensino e aprendizagem.

\section{Referências}

AUSUBEL, D. P.; NOVAK, J. D.; HANESIAN, H. Psicología educativa: Un punto de vista cognoscitivo. 2 ed. México: Trillas, 1983. 
BARDIN, L. Análise de conteúdo. São Paulo: Edições 70, 2011

BECK, J. L.The Weight of a Heavy Hour: Understanding Teacher Experiences of Work Intensification. McGill Journal of Education, v. 52, n 3, p. 617-636, 2017.

BORDIEU, P. A reprodução. Rio de Janeiro: Francisco Alves, 1992.

CAMAS, N. P. V.; BRITO, G. S. Metodologias ativas: uma discussão acerca das possibilidades práticas na educação continuada de professores do ensino superior. Rev. Diálogo Educ., v. 17, n. 52, p. 311-336, abr./jun. 2017.

CAMAS N.P.V.; MANDAJI, M.; RIBEIRO, R.A.; MENGALLI, N.M. Professor e cultura digital: reflexões teóricas acerca dos novos desafios na ação formadora para nosso século. Revista Reflexão e Ação, v. 21, n. 2, p. 179-198, jul./dez. 2013.

CAMAS, N. V. P.; FOFONCA, E.; HARDAGH, C. C. Pesquisa Narrativa e Curadoria de Conhecimento na Cultura Digital. RE@D -Revista de Educação a Distância e Elearning, Portugal. v. 3 n. 1.p.115 - 130, 2020.

CASTELLS, M. A sociedade em rede. São Paulo: Paz e Terra, 2009.

CLANDINI, D. J.; CONNELLY, F.M. Teachers' Professional Knowledge Landscapes: Teacher Stories-Stories of Teachers-School Stories-Stories of Schools. Educational Researcher, v. 25, n. 3, p. 24-30, abr., 1996. DOI: 10.3102/0013189X025003024

CONTRERAS, J. A autonomia de professores. 2a ed. São Paulo: Cortez, 2012.

CORTELA. M. S.; DIMENSTEIN, G. A era da curadoria: o que importa é saber o que importa. Campinas, SP: Papirus 7 mares, 2015.

CRESWELL, J. W. Investigação Qualitativa e Projeto de Pesquisa: Escolhendo Entre Cinco Abordagens. Porto Alegre: Penso, 2014.

CReswell, J. W. Projeto de Pesquisa: Métodos Qualitativos, Quantitativos e Misto. Trad. Magda Lopes. 3 ed. Porto Alegre: Artmed, 2010.

FIORENTINI, D. Pesquisar práticas colaborativas ou pesquisar colaborativamente? In: MORAES, Marialice de \& PAZ-KLAVA, Carolina. Comunidades interativas de aprendizagem. Palhoça: UnisulVirtual, 2004.

FOFONCA, E.; CAMAS, N. P. V. A curadoria de conhecimento em ambiência imersivas e os processos formativos de professores da educação básica com metodologias inovadoras. Revista Intersaberes, v. 14, n. 31, p. 7-19, jan.-mar. 2019.

FREIRE, P. Pedagogia do oprimido. $1^{\text {a }}$ ed. Rio de Janeiro: Paz e Terra, 1974.

GAUTHIER, C.; MARTINEAU, S.; DESBIENS, J-F.; MELO, A.; SIMARD, D. Por uma teoria da pedagogia: pesquisas contemporâneas sobre o saber docente. $3^{\mathrm{a}}$ ed. Ijuí: Ed. Unijuí, 2013.

GOODSON, I. Currículo, narrativa e o futuro social. Revista Brasileira de Educação [online]. 2007, v. 12, n. 35 [Acessado 3 setembro 2021], pp. 241-252. Disponível em: <https://doi.org/10.1590/S1413-24782007000200005>. Epub 25 Set 2007. ISSN 1809-449X. https://doi.org/10.1590/S1413-24782007000200005.

KEMCZINSKI, A.; MAREK, J.; HOUNSELL, M. da S.; GASPARINI. Colaboração E Cooperação - Pertinência, Concorrência Ou Complementaridade. Revista Produção OnLine, Vol. 7, Num. 3, p. 1-16, novembro 2007. 
LÉVY, P. Cibercultura. Trad. Carlos Irineu da Costa. São Paulo: Editora 34, 2009.

MARTINO, L. M. S. Teoria das Mídias Digitais: Linguagens, Ambientes, Redes. São Paulo: Ed. Vozes, 2014.

MATURANA, H. R.; VARELA, F.J.G. A árvore do conhecimento: as bases biológicas da compreensão humana. $2^{\text {a }}$ Ed. Tradução Humberto Mariotti e Lia Diskin. São Paulo: Palas Athenas, 2002.

LIMA, M. S. L. Docência e pesquisa em formação de professores: caminhos que se cruzam nas cartas pedagógicas. In: PIMENTA, S. G.; GHEDIN, E.; FRANCO, M. A. S. (Org.). Pesquisa em educação: alternativas investigativas com objetos complexos. São Paulo: Loyola, 2006.

MORAES, M. C. (Org). Transdisciplinaridade, criatividade e educação: fundamentos ontológicos e epistemológicos. Colaboração Juan Miguel Batalloso. Campinas, SP: Papirus, 2015

PANITZ, T. A definition of collaborative vs cooperative learning. Commonwealth of Learnig, $1996 . \quad$ Disponível em: http://colccti.colfinder.org/sites/default/files/a_definition_of_collaborative_vs_coop erative_learning.pdf. Acessado em: dez./2019.

PERRENOUD. P. A prática reflexiva no ofício de professor: profissionalização e razão pedagógica. Porto Alegre: Artmed, 2002.

PÉREZ GÓMEZ, A. Educação na Era Digital: a escola educativa. Porto Alegre: Penso, 2015.

SACRISTÁN, J. G.; GÓMEZ, A. I. Pérez. Compreender e transformar o ensino. Porto Alegre: Artmed, 2000.

SANTOMÉ. J. T. Globalização e interdisciplinaridade. Porto Alegre: Artmed, 1998.

SANTAELLA, L. O Papel Lúdico na Aprendizagem. Revista Teias, v. 13, n. 30, p. 185195, set./dez. 2012.

SCHÖN, D. A. Educando o profissional reflexivo: um novo design para o ensino e a aprendizagem. Trad. Roberto Cataldo Costa. Porto Alegre: Artmed, 2000.

SOUSA, M.G.S; CABRAL, C.L.O. A narrativa como opção metodológica de pesquisa e formação de professores. Horizontes, Itatiba, v. 33, n. 2, p. 149-158, jul./dez. 2015.

TARDIF, M. Saberes docentes e formação profissional. Petrópolis: Vozes, 2002.

TARDIF. M. Saberes profissionais dos professores e conhecimentos universitários: elementos para uma epistemologia da prática profissional dos professores e suas consequências em relação à formação para o magistério. Revista Brasileira de Educação, Rio de Janeiro: ANPEd ; Campinas: Autores Associados, n. 13, p. 5-24, jan.-abr. 2000.

VAN DER LINDEN, J.; ERKENS, G.; SCHMIDT, H.; RENSHAW, P. Collaborative Learning. In: SIMONS R.J.; VAN DER LINDEN J.; DUFFY T. (Eds). New York: Kluwer Academic Publishers, 2000. DOI https://doi.org/10.1007/0-306-47614-2_3

UNESCO. Diretrizes para Recursos Educacionais Abertos (REA) no Ensino Superior. Tradução UNESCO. Paris: Unesco, 2015. Disponível em: https://unesdoc.unesco.org/ark:/48223/pf0000232852 
VYGOTSKY, L. S. A formação social da mente: o desenvolvimento dos processos psicológicos superiores. São Paulo: Martins Fontes, 1991.

Autores

Fernando Roberto Amorim Souza Universidade Tecnológica Federal do Paraná Mestrado / Educação Programa de Pós-Graduação em Formação Científica, Educacional e Tecnológica Ensino de Ciências fernandoamorim.ifpr@gmail.com

Nuria Pons Vilardell Camas Universidade Federal do Paraná - UFPR Doutorado em Educação Programa de pós-graduação em Educação: Teoria e Prática de Ensino (UFPR) e Programa de Pós Graduação em PPGFCET -UTFPR

Tecnologias e Educação nuriapons@gmail.com

João Amadeus Pereira Alves Universidade Tecnológica Federal do Paraná Doutor Formação Científica, Educacional e Tecnológica Ensino de Ciências japalves@yahoo.com.br 